\title{
Global burden of chronic pulmonary aspergillosis complicating sarcoidosis
}

\author{
David W. Denning*,\#, Alex Pleuvry ${ }^{\top}$ and Donald C. Cole ${ }^{+}$
}

ABSTRACT: Chronic pulmonary aspergillosis (CPA) may complicate pulmonary sarcoidosis. We re-estimated the global burden of sarcoidosis and the burden of CPA complicating sarcoidosis.

We searched the literature and reference lists of retrieved papers to identify all published sarcoidosis incidence and prevalence data. We estimated the frequency of CPA from 11 papers relating to $>3,000$ patients with sarcoidosis to derive CPA patient numbers. We applied an annual attrition rate of $15 \%$ (range 10-25\%) to estimate the global burden of CPA.

We estimate that the annual incidence of sarcoidosis is 344,000 patients worldwide and the prevalence is $\sim 1,238,000$ cases, distributed as follows: 165,979 in Europe, 224,000 in the Americas, 492,892 in Africa, 80,023 in the Eastern Mediterranean, 41,660 in the West Pacific and 234,010 in Southeast Asia. CPA complicates sarcoidosis in $3-12 \%$ of cases. Using a $6 \%$ frequency, we estimate a global burden of 71,907 (range 35,954-143,815 (3-12\%)) CPA cases complicating sarcoidosis, with $24 \%$ and $37 \%$ of cases estimated to be present in the Americas and Africa, because of the higher incidence of sarcoidosis in black people.

As CPA responds to long-term antifungal therapy, which may prevent life-threatening haemoptysis, screening periodically for CPA in those with pulmonary sarcoidosis may be important, especially in patients requiring corticosteroid therapy.

KEYWORDS: Aspergilloma, Aspergillus fungal ball, burden of disease, cavitation, fibrosis, lobectomy, precipitins

C hronic pulmonary aspergillosis (CPA) complicates fibrocystic sarcoidosis with one or more aspergillomas in a pre-existing cavity $[1,2]$. Invasive aspergillosis may supervene if highdose corticosteroids are used. Many other conditions can be complicated by CPA, although data from the National Aspergillosis Centre, Manchester, UK, implicates sarcoidosis in $7.1 \%$ of our patients [3]. Other conditions include prior pulmonary tuberculosis, allergic bronchopulmonary aspergillosis (ABPA), pneumothorax, bullous lung disease, nontuberculous mycobacterial pulmonary infection and chronic obstructive pulmonary disease (COPD) [1,3].

The morbidity of CPA includes marked systemic and pulmonary symptoms, such as weight loss, fatigue, breathlessness and haemoptysis [4, 5], some of which may be masked by long term corticosteroids. Antifungal therapy is effective in ameliorating symptoms and reducing recurrence of haemoptysis in $>60 \%$ of patients [4-10], and may reduce progressive lung fibrosis. Overall, treated CPA has a 20-33\% short-term mortality and a $50 \%$ mortality over 5 yrs $[6,11]$, but one small cohort showed that almost all patients with sarcoidosis and CPA had died within 2 yrs [12].

In this study, we aimed to use published clinical and population data as inputs to model estimates of the likely global burden of sarcoidosis, and then estimate the burden of CPA related to sarcoidosis worldwide. As numerous population estimates for sarcoidosis are not available, and there are few high-quality prospective cohort studies of CPA in the context of pulmonary sarcoidosis, our approach has been to use literature values where they exist and extrapolate from these globally. By necessity, our estimates are crude, perhaps appropriately referred to as "Fermi calculations", after the Nobel-prize winning physicist Enrico Fermi. Nonetheless, order of magnitude estimates are still useful and can provide a basis for future more precise studies.

\section{METHODS}

We estimated adult sarcoidosis and CPA burden by World Health Organization (WHO) region and for the largest countries as shown in figure 1.
AFFILIATIONS

*The University of Manchester, Manchester Academic Health Science Centre,

\#The National Aspergillosis Centre, University Hospital of South Manchester, Manchester, and -Oncalex, Whaley Bridge, UK +Dalla Lana School of Public Health, University of Toronto, Toronto, ON, Canada.

CORRESPONDENCE

D.W. Denning

2nd Floor Education and Research Centre

Wythenshawe Hospital

Southmoor Road

Manchester

M23 9LT

UK

E-mail: ddenning@manchester.ac.uk

Received:

Dec 272011

Accepted after revision:

May 312012

First published online:

June 272012 


\begin{tabular}{|c|c|c|c|c|c|c|c|}
\hline $\begin{array}{l}\text { ncidence or prevalence } \\
\text { of sarcoidosis per } \\
100000 \text { per country }\end{array}$ & $x$ & $\begin{array}{c}\text { Conversion from incidence } \\
\text { to prevalence using } \\
\text { an "international ratio" } \\
\text { of } 3.7 \text { (most countries) }\end{array}$ & & $\begin{array}{c}6 \% \text { (best estimate) } \\
\text { range } 3-12 \% \text { ( } \% \text { with } \\
\text { cavities likely to be CPA) }\end{array}$ & & $\begin{array}{l}\text { Total CPA annual } \\
\text { prevalence } \\
\text { complicating } \\
\text { sarcoidosis }\end{array}$ & $\begin{array}{l}15 \% \text { (range } 10-25 \% \text { ) } \\
\text { annual attrition then applied to } \\
\text { compute } 5 \text {-yr period prevalence } \\
\text { of CPA complicating sarcoidosis }\end{array}$ \\
\hline
\end{tabular}

FIGURE 1. Factors used in estimation of chronic pulmonary aspergillosis (CPA) complicating sarcoidosis.

We searched the literature extensively, including book chapters, for population-based estimates of sarcoidosis, and then separately for aspergillosis complicating sarcoidosis. Search terms included "sarcoidosis" with "epidemiology", "frequency", "rate", "incidence" and "prevalence". References of retrieved papers were also examined.

\section{Sarcoidosis burden}

For sarcoidosis, we had a combination of incidence and prevalence studies, also with wide variation in estimates both in existing reviews (table S1) and primary studies (table S2).

We chose an overall US incidence of 13.8 out of 100,000 , a weighted average of the highest among female AfricanAmericans (39.1 out of 100,000) and the lowest among male Caucasian Americans (9.6 out of 100,000) [13]. Country-specific data for Portugal, Sweden, Denmark, Belgium and Korea were quoted from THOMEeR et al. [14], and older data for Germany, the Netherlands, Italy, Norway, Czechoslovakia, Hungary, Poland, Yugoslavia, Canada, Argentina, Brazil, Australia and New Zealand are summarised by LEITCH [15].

Prevalence studies demonstrate similar variation by region and ethnicity, being more common in northern Europeans and black people living in the USA. Proportions per 100,000 population ranged from 0.1 to 64 [14-16]. Available individual country prevalences were used for the UK [17], Israel [18], Iceland [19], Spain (pulmonary sarcoidosis only) [20], Greece [21], Switzerland [22], Japan [23] and the USA [24]. Extrapolations were made as follows: China and Vietnam were assumed to be similar to Singapore Chinese [25]; India, Pakistan and Bangladesh, to Singapore Indians [25]; Philippines, Thailand and Indonesia, to Singapore Malaysians [25]; Congo, Nigeria and Ethiopia, to UK black people [26]; Egypt and Iran, to Turkey [27]; and Russia, to Finland [23].

To move to a common metric, we decided to convert annual incidence to prevalence for a 5-yr period. Published prevalence/incidence ratios vary from 2.5 in Finland [23], through 3.7 based on Japanese and Greek data [21, 23], to 6.7 currently active/incident cases in Switzerland [22] and 7.8 in Belgium [15], so we settled on a conservative estimate of 3.7. We started with countries with populations exceeding 50 million and extended to each WHO region by assuming similar values for countries with populations $<50$ million as for those with $>50$ million.

\section{CPA in sarcoidosis}

We next estimated the frequency of CPA in sarcoidosis using a "scoping review" methodology [28]. The relative proportion of patients with sarcoidosis who have parenchymal pulmonary disease varies from $66 \%$ to $90 \%$ (tables S1 and S2) [15, 29], but most do not have cavitation (table 1). We searched the literature extensively for series of sarcoidosis cases containing details of the rate of cavitation, aspergilloma and/or
Aspergillus serology. Search terms included "sarcoidosis" with "aspergilloma", "aspergillosis", "case series", "cohort", "longitudinal, "follow up", "outcome" or "mortality", as well as the reference lists of the articles obtained. Grey literature, such as conference abstracts and doctoral theses, were not searched. Our files of pre-1990 aspergillosis papers were also searched by hand. Every paper retrieved with cohort information on sarcoidosis was read, and accepted if a denominator provided rates of cavitation and information on aspergillomas visible radiologically and/or Aspergillus immunoglobulin (Ig)G (precipitins) serology (table 1).

\section{Handling attrition among CPA cases}

The time-frames of observation of sarcoidosis varied substantially, and one small study from the USA indicated that most patients with pulmonary sarcoidosis complicated by CPA had died after 2 yrs [12]. However, this is not our experience and most of our patients with CPA complicating sarcoidosis are alive and stable $\geqslant 5$ yrs after diagnosis. Given the lack of periodic screening for CPA, it is likely that most cases of CPA are identified in existing cohorts over many years. Hence, these cohorts essentially provide a period prevalence of variable duration. For consistency, we applied an annual 15\% attrition (mostly death and occasionally transplantation) rate to our prevalence estimates to establish disease burden for a 5-yr period.

\section{RESULTS \\ Sarcoidosis}

We estimated that the annual incidence of sarcoidosis is 344,000 patients worldwide and therefore the prevalence is $\sim 1,238,000$ cases, distributed as follows: 165,979 in Europe, 224,000 in the Americas, 492,892 in Africa, 80,023 in the East Mediterranean, 41,660 in the West Pacific and 234,010 in Southeast Asia. The annual incident cases and prevalence for the countries with populations $>50$ million are shown in table 2 and prevalence for all countries that have estimated it in figure 2. The remarkably low burden of sarcoidosis in some countries, such as Brazil and Mexico, is a function of a low annual incidence of $<0.3$ out of 100,000 (351 cases in Mexico), which contrasts with the high annual incidence in the USA of 13.8 out of 100,000 (41,734 cases). Cleary, some countries' burden is an estimate based on figures from other countries, notably Nigeria, Ethiopia and the Democratic Republic of Congo, because of some ethnicity similarities but with no environmental commonality (which may or may not be important).

\section{CPA complicating sarcoidosis}

There was much variation in the frequency of cavitation and fungal ball observation in sarcoidosis (table 1). In US studies up to 1984 , cavitation rates varied from $2 \%$ to $12.5 \%$ and aspergilloma rates from $1 \%$ to $11 \%$ [29-36]. In later studies from Israel, Turkey and France, aspergilloma rates varied from $0 \%$ to $2.1 \%[1,37,38]$. In particular, in France, Hours et al. [1] found 41 $(3.9 \%)$ out of 1,060 patients with pulmonary cavitation in those 
TABLE 1 Sources providing data on the frequency of chronic pulmonary aspergillosis in patients with sarcoidosis

\begin{tabular}{|c|c|c|c|c|c|c|c|c|}
\hline Year & Country & $\begin{array}{l}\text { Sampling } \\
\text { method }\end{array}$ & Imaging & $\begin{array}{c}\text { Denominator } \\
n\end{array}$ & Pulmonary cavitation & Aspergilloma & $\begin{array}{l}\text { Aspergillus } \\
\text { precipitins }\end{array}$ & [Ref.] \\
\hline 1970 & USA & Long/retro & CXR & 300 & $25(12.5)$ & $10(4)$ & ND & {$[31]$} \\
\hline 1973 & USA & Long/retro & CXR & 150 & $42(28)^{\#}$ & $1(0.8)$ & ND & {$[32]$} \\
\hline 1976 & USA & Long/retro & CXR & 68 & NS & $3(4.4)$ & ND & {$[33]$} \\
\hline 1984 & USA & Cross-sect & CT & 100 & NS & $10(10)$ & $12(12)$ & [29] \\
\hline 1985 & Israel & Long/retro & CXR & 197 & $50(25)^{\#}$ & 0 & ND & {$[36]$} \\
\hline 2002 & Turkey & Cross-sect & $\mathrm{CT}$ & 70 & $2(2.9)$ & NS & ND & {$[37]$} \\
\hline 2008 & France & Long/retro & СТ & 1060 & $41(3.9)$ & $21(2.1)$ & ND & [1] \\
\hline 2011 & USA & Long/retro & СТ & 427 & NS & $10(2.3)$ & NS & {$[38]$} \\
\hline
\end{tabular}

Data are presented as $\mathrm{n}(\%)$, unless otherwise stated. Long: Iongitudinal; retro: retrospective; Cross-sect: cross-sectional; CXR: chest radiograph only; CT: chest radiograph and computed tomography of the thorax; NS: not stated; ND: not determined. ${ }^{*}$ : incidence of fibrosis, not cavitation, which was not stated.

with pulmonary sarcoidosis. In 18 patients, an aspergilloma was present on initial computed tomography scan and, in three more, one developed during follow-up, a $51 \%$ rate in those with cavitation and a $2 \%$ rate overall. In the USA, PENA et al. [36] found 10 patients with an aspergilloma among $427(2.3 \%)$ patients with pulmonary sarcoidosis. Neither study utilised

TABLE 2 Estimated incidence and prevalence of sarcoidosis and chronic pulmonary aspergillosis (CPA) complicating sarcoidosis in countries with populations exceeding 50 million

\begin{tabular}{|c|c|c|c|c|c|c|c|}
\hline \multirow[t]{2}{*}{ Country } & \multirow{2}{*}{$\begin{array}{l}\text { Population in } \\
2005 \text { [39] }\end{array}$} & \multicolumn{4}{|c|}{ Sarcoidosis } & \multicolumn{2}{|c|}{ CPA 6\% (range 3-12\%) } \\
\hline & & $\begin{array}{l}\text { Incidence per } \\
100000 \text { per year }\end{array}$ & $\begin{array}{l}\text { Incidence } \\
\text { cases }\end{array}$ & $\begin{array}{l}\text { Prevalence } \\
\text { per } 100000\end{array}$ & $\begin{array}{l}\text { Prevalence } \\
\text { cases }\end{array}$ & $\begin{array}{c}\text { Annual } \\
\text { incident cases }\end{array}$ & $\begin{array}{l}\text { 5-yr period prevalence } \\
\text { cases (less attrition) }\end{array}$ \\
\hline China & 1312253000 & $0.56^{\#}$ & 7349 & 2.1 & 27190 & $441(220-882)$ & $1387(693-2773)$ \\
\hline India & 1130618000 & $4.57^{\circ}$ & 51669 & 16.9 & 191176 & $3100(1550-6200)$ & $9750(4875-19500)$ \\
\hline Brazil & 186075000 & 0.1 & 101 & 0.2 & 372 & $6(3-12)$ & $19(9-38)$ \\
\hline Pakistan & 165816000 & $4.57^{\circ}$ & 7578 & 16.9 & 28038 & 455 (227-909) & $1430(715-2860)$ \\
\hline Bangladesh & 153122000 & $4.57^{\circ}$ & 6998 & 16.9 & 25891 & $420(210-840)$ & $1320(660-2641)$ \\
\hline Russia & 143470000 & $11^{+}$ & 16356 & 28 & 40459 & $1674(837-3347)$ & $2063(1032-4127)$ \\
\hline Nigeria & 140879000 & $19.8^{\S}$ & 27894 & 73.3 & 103208 & $981(491-1963)$ & $5264(2632-10527)$ \\
\hline Germany & 82409000 & 4 & 3118 & 14 & 11537 & $187(94-374)$ & $588(294-1177)$ \\
\hline Egypt & 77154000 & $4^{f}$ & 3086 & 14.8 & 11419 & $185(93-370)$ & $582(291-1165)$ \\
\hline Ethiopia & 74661000 & $19.8^{5}$ & 14783 & 73.3 & 54697 & $887(443-1774)$ & 2790 (1395-5579) \\
\hline Turkey & 71169000 & 4 & 2847 & 14.8 & 10533 & $171(85-342)$ & 537 (269-1074) \\
\hline Iran & 70765000 & $4^{f}$ & 2831 & 14.8 & 10473 & $170(85-340)$ & $534(267-1068)$ \\
\hline Thailand & 65946000 & $1.3^{\circ}$ & 857 & 4.8 & 3172 & $51(26-103)$ & $162(81-324)$ \\
\hline France & 61013000 & 3 & 1649 & 10 & 6101 & 99 (49-198) & 311 (156-622) \\
\hline UK & 60261000 & 5 & 4000 & 27 & 16270 & $240(120-480)$ & $830(415-1660)$ \\
\hline (DR) Congo & 59077000 & $19.8^{5}$ & 11697 & 73.3 & 43280 & 702 (351-1404) & $2207(1104-4415)$ \\
\hline Italy & 58645000 & 2 & 1427 & 9 & 5278 & $86(43-171)$ & 269 (135-538) \\
\hline
\end{tabular}

DR: Democratic Republic. ${ }^{\#}$ : assumed to be similar to Singaporean Chinese; "

s: assumed to be similar to UK black people; ${ }^{f}$ : assumed to be similar to Turkey. 


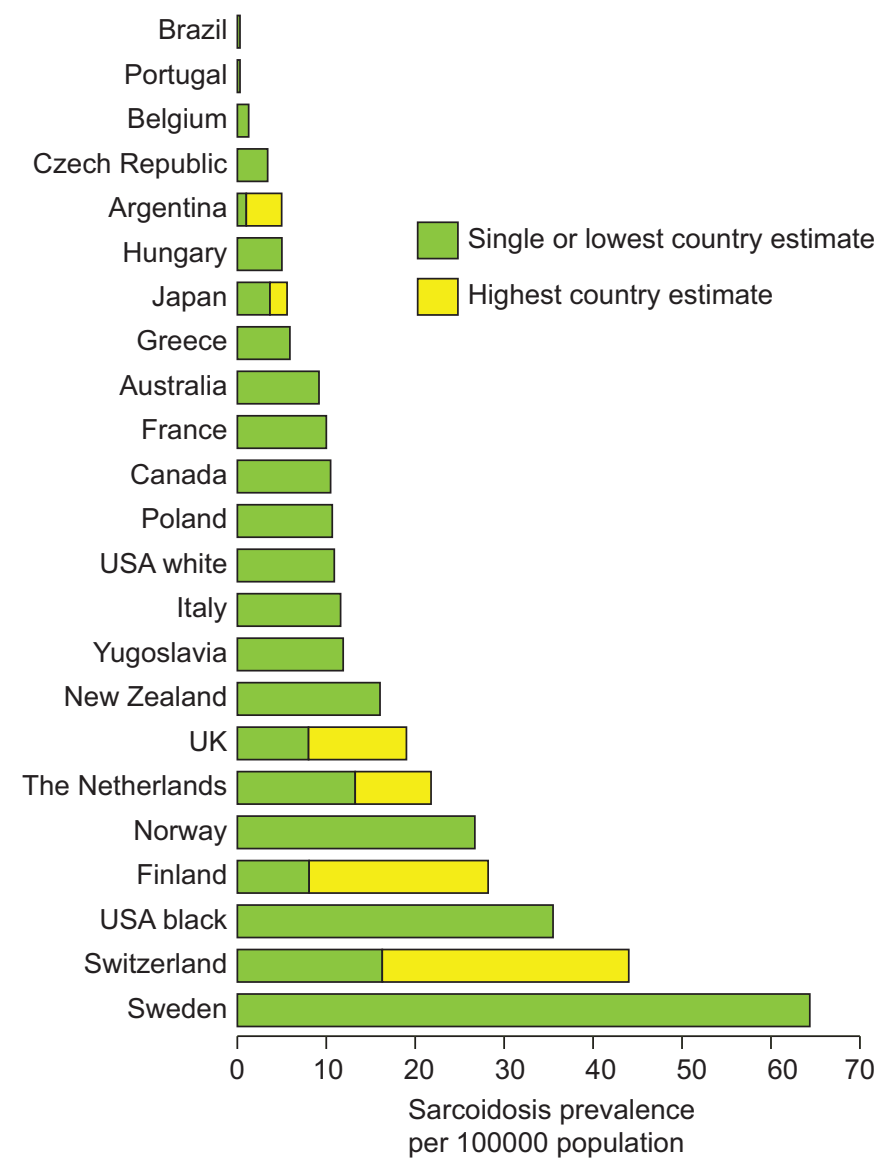

FIGURE 2. Variable published prevalence per 100,000 population of pulmonary sarcoidosis in different countries, and in the USA between black and white people. If more than one estimate is available, then both are presented. Rates vary from 0.2 out of 100,000 in Brazil to 64.4 out of 100,000 in Sweden. Data from supplementary tables S1 and S2.

Aspergillus serology, unlike WOLLSCHLAGER and KHAN [29] in 1984. Synthesising this literature, we used a best estimate of $6 \%$ prevalence of CPA in patients with sarcoidosis for all countries, with deterministic sensitivity analyses using a range from a low of $3 \%$ to a high of $12 \%$, recognising the somewhat arbitrary selection of these values.

The annual incidence of CPA complicating sarcoidosis is estimated to be 20,640 patients using the $6 \%$ proportion. The 5-yr period prevalence after attrition is estimated to be 71,907 (range 35,954-143,815; 3-12\%) patients worldwide. Table 1 shows the estimated CPA burden in the countries with a population $>50$ million, and includes lower and higher estimates of $3 \%$ and $12 \%$ alongside the best estimate of $6 \%$. Overall, $24 \%$ and $37 \%$ of cases are thought to be present in the Americas and Africa, respectively, because of the higher incidence of sarcoidosis in black people. In countries with a population of $>50$ million, the burden is estimated to be 39,127 patients, to which India 9,750 (range 4,875-19,500) and the USA 7,875 (range $3,938-15,750$ ) contribute nearly $45 \%$ of the cases.

\section{DISCUSSION}

Sarcoidosis represents $7-17 \%$ of CPA cases in our and other series [3]. There are substantial datasets describing the incidence and prevalence of sarcoidosis from some countries, but unfortunately not from many of the large Asian or South American countries. The marked ethnic differences illustrated by the Singaporean and London data are remarkable. The Chinese, Malay and Indian incidence rates in Singapore were 0.56, 1.3 and 4.57 per 100,000 [25] and, in London, the rates of Caucasians, Indians and black people were 1.5, 16.8 and 19.8 per 100,000 [26]. In the USA, the male Caucasian rate was 9.6, whereas it was 29.8 in black people [24]. NunEs et al. [40] proposed a global annual incidence of sarcoidosis of 17.8 per 100,000 . If applied to the global population aged $>25$ yrs in 2005 [39], 620,152 new cases would be expected annually. This figure appears higher than our figure of 370,912 , but given that "the Fermi method" provides approximate estimates with a precision of about one $\log$, then they are of the same magnitude. There is substantial uncertainty in annual incidence rates in very large populations, notably China, Indonesia, Africa and Brazil. Locally ascertained data would be most helpful in improving the accuracy of our estimates.

The primary means we have used to estimate CPA burden is radiographic. However, our own data suggest that only $\sim 25 \%$ of patients with CPA have an aspergilloma [7], the remainder having one or more cavities. This may be problematic in some patient groups who develop CPA, notably those with sarcoidosis in whom pulmonary cavities pre-date the development of CPA. In addition to the radiographic image of an aspergilloma in sarcoidosis, the diagnosis of CPA usually relies on positive Aspergillus IgG serology. 90\% of cases of CPA have detectable Aspergillus fumigatus precipitins or other IgG antibodies, with some variation between assays [41, 42]. In other patients, the diagnosis relies on biopsy and/or culture. While almost all cases of CPA are caused by A. fumigatus, rare patients are described with Aspergillus niger, Aspergillus flavus and Aspergillus nidulans infection [5, 43-45], with the implication that IgG antibody to A. fumigatus may not be present if infection is due to these species. So CPA case ascertainment is likely to be incomplete in sarcoidosis. Other diagnostic tests, such as histological demonstration of hyphae in biopsied cavities, cultures of Aspergillus spp. and/or PCR Aspergillus assays [46] may assist in diagnosis.

As patients with fibrocystic pulmonary sarcoidosis have pulmonary cavities, the criteria for diagnosis of CPA are either the presence of a fungal ball and/or serum Aspergillus IgG antibodies. These were prospectively assessed in only one study [29], and this study found the highest rate of CPA complicating sarcoidosis. This suggests that, in the absence of active testing for CPA, underdiagnosis plagues adequate detection of CPA among this clinical population with chronic respiratory disease. There may be ethnic differences in the rate of $\mathrm{CPA}$, or in its progression or other manifestations, but data are currently lacking. One surprise is the lack of reports of CPA or aspergilloma from Scandinavia, given the high prevalence of sarcoidosis there.

A few CPA cases (1-17\%) undergo curative surgery, usually within the first year of CPA diagnosis [47], but sometimes the outcome from this is death. In addition, CPA itself is a progressive disease with an annual mortality varying from $\sim 10 \%$ [11] to $\sim 30 \%$ after referral to hospital [6]. We have directly accounted for this in our 5-yr period prevalence 
estimates of CPA by introducing an annual attrition rate of $15 \%$ (range $10-25 \%$ ). However, a mortality rate of nearly $100 \%$ over 2 yrs was seen in a small US series from the 1980s [12], and it is possible that we have significantly underestimated attrition. In our experience, the severity of the combination of the underlying pulmonary disease, combined with the extent of lung destruction caused by CPA, is the major determinant of survival. No study has provided information on the relationship between lung function and outcome, in the context of CPA, to allow this to be modelled.

CPA complicates several different pulmonary diseases other than sarcoidosis, notably those with classical pulmonary tuberculosis, nontuberculous mycobacterial infection, ABPA and COPD [3]. We have estimated the frequency of CPA as a sequel to tuberculosis and estimate the annual global incident cases to be 372,000 and the 5 -yr period prevalence 1.17 million, also assuming a $15 \%$ attrition [48]. We have also estimated the global 5-yr period prevalence of CPA complicating ABPA at 345,000 persons, using a $15 \%$ attrition rate DENNING et al. [49]. Therefore, our estimates rank sarcoidosis as a relatively uncommon cause of CPA, especially considering that COPD, which we have not estimated, is the most common underlying diagnosis in our experience [7].

While some genetic risk factors for CPA are probably important in the development of CPA, such as a Toll-like receptor 4 polymorphism or cytokine aberrations [50, 51], the use of corticosteroids could be either helpful or a hindrance. Corticosteroid suppression of the aberrant inflammatory response in sarcoidosis may prevent ongoing lung fibrosis and cavity formation. However, such suppression also leaves the patient open to progression of chronic to invasive aspergillosis, which may be fatal [52-54]. Possibly, the use of oral antifungal agents to prevent progression of aspergillosis, in the face of corticosteroid use, would be helpful, but such management has never been formally studied. In any case, intravenous and long-term oral antifungal therapy reduces morbidity and mortality in these patients [4-10]. Indeed, there are even emerging data suggesting that antifungal therapy may be helpful in sarcoidosis directly, through an uncertain mechanism of action [55]. Screening with Aspergillus IgG antibody testing may be a cost-effective means of identifying patients with CPA early in fibrocystic sarcoidosis, permitting explicit decisions around both corticosteroid and antifungal medical management.

\section{STATEMENT OF INTEREST}

Statements of interest for all authors can be found at www.erj. ersjournals.com/site/misc/statements.xhtml

\section{ACKNOWLEDGEMENTS}

We are indebted to J. Gill and library staff at the University Hospital of South Manchester, Manchester, UK, for sourcing the papers.

\section{REFERENCES}

1 Hours S, Nunes H, Kambouchner M, et al. Pulmonary cavitary sarcoidosis: clinico-radiologic characteristics and natural history of a rare form of sarcoidosis. Medicine (Baltimore) 2008; 87: 142-151.
2 Denning DW. Chronic aspergillosis. In: Aspergillus fumigatus and Aspergillosis. Latge JP, Steinbach WJ, eds. Washington, ASM Press, 2009.

3 Smith N, Denning DW. Underlying pulmonary disease frequency in patients with chronic pulmonary aspergillosis. Eur Respir J 2011; 37: 865-872.

4 Denning DW, Riniotis K, Dobrashian R, et al. Chronic cavitary and fibrosing pulmonary and pleural aspergillosis: case series, proposed nomenclature change, and review. Clin Infect Dis 2003; 37: Suppl. 3, S265-S280.

5 Camuset J, Nunes H, Dombret MC, et al. Treatment of chronic pulmonary aspergillosis by voriconazole in nonimmunocompromised patients. Chest 2007; 31: 1435-1441.

6 Nam HS, Jeon K, Um SW, et al. Clinical characteristics and treatment outcomes of chronic necrotizing pulmonary aspergillosis: a review of 43 cases. Int J Infect Dis 2010; 14: e479-e482.

7 Felton TW, Baxter C, Roberts S, et al. Efficacy and safety of posaconazole for chronic pulmonary aspergillosis. Clin Infect Dis 2010; 51: 1383-1391.

8 Jain LR, Denning DW. The efficacy and tolerability of voriconazole in the treatment of chronic cavitary pulmonary aspergillosis. J Infect 2006; 52: e133.

9 Sambatakou H, Dupont B, Lode, H, et al. Voriconazole treatment for subacute invasive and chronic pulmonary aspergillosis. Am J Med 2006; 119: 527.

10 Kohno S, Izumikawa K, Ogawa K, et al. Intravenous micafungin versus voriconazole for chronic pulmonary aspergillosis: a multicenter trial in Japan. J Infect 2010; 61: 410-418.

11 Jewkes J, Kay PH, Paneth M, et al. Pulmonary aspergilloma: analysis of prognosis in relation to haemoptysis and survey of treatment. Thorax 1983; 38: 572-578.

12 Tomlinson, JR, Sahn SA. Aspergilloma in sarcoid and tuberculosis. Chest 1987; 92: 505-508.

13 Rybicki BA, Major M, Popovich J Jr, et al. Racial differences in sarcoidosis incidence: a 5-year study in a health maintenance organization. Am J Epidemiol 1997; 145: 234-241.

14 Thomeer MJ, Demedts M, Wuyts W. Epidemiology of sarcoidosis. Eur Respir Monogr 2005; 32: 13-22.

15 Leitch AG. Sarcoidosis. In: Seaton A, Seaton D, Leitch AG, eds. Crofton and Douglas's Respiratory Diseases. 5th Edn. London, Blackwell Science, 2000; pp 1035-1062.

16 Hosoda Y, Yamaguchi M, Hiraga Y. Global epidemiology of sarcoidosis. What story do prevalence and incidence tell us? Clin Chest Med 1997; 18: 681-694.

17 Gribbin J, Hubbard RB, Le Jeune I, et al. Incidence and mortality of idiopathic pulmonary fibrosis and sarcoidosis in the UK. Thorax 2006; 61: 980-985.

18 Yigla M, Badarna-Abu-Ria N, Tov N, et al. Sarcoidosis in northern Israel; clinical characteristics of 120 patients. Sarcoidosis Vasc Diffuse Lung Dis 2002; 19: 220-226.

19 Haraldsdottir SO, Jörundsdóttir KB, Yngvason F, et al. Sarcoidosis in Iceland 1981-2003. Laeknabladid 2007; 93: 105-109.

20 López-Campos JL, Rodríguez-Becerra E, Neumosur Task Group, et al. Incidence of interstitial lung diseases in the south of Spain 1998-2000: the RENIA study. Eur J Epidemiol 2004; 19: 155-161.

21 Karakatsani A, Papakosta D, Rapti A, et al. Epidemiology of interstitial lung diseases in Greece. Respir Med 2009; 103: 1122-1129.

22 Deubelbeiss U, Gemperli A, Schindler C, et al. Prevalence of sarcoidosis in Switzerland is associated with environmental factors. Eur Respir J 2010; 35: 1088-1097.

23 Pietinalho A, Hiraga Y, Hosoda Y, et al. The frequency of sarcoidosis in Finland and Hokkaido, Japan. A comparative epidemiological study. Sarcoidosis 1995; 12: 61-67.

24 Rybicki BA, Iannuzzi MC. Epidemiology of sarcoidosis: recent advances and future prospects. Semin Respir Crit Care Med 2007; 28: 22-35. 
25 Anantham D, Ong SJ, Chuah KL, et al. Sarcoidosis in Singapore: epidemiology, clinical presentation and ethnic differences. Respirology 2007; 12: 355-360.

26 Edmonstone WM, Wilson WG, Sarcoidosis in caucasians, blacks and asians in London. Br J Dis Chest 1985; 79: 27-36.

27 Musellim B, Kumbasar OO, Ongen G, et al. Epidemiological features of Turkish patients with sarcoidosis. Respir Med 2009; 103: 907-912.

28 Arksey H, O'Malley L. Scoping studies: towards a methodological framework. Int J Social Res Methodol 2005; 8: 19-32.

29 Wollschlager C, Khan F. Aspergillomas complicating sarcoidosis. A prospective study in 100 patients. Chest 1984; 86: 585-588.

30 Maycock RL, Bertrand P, Morrison CE, et al. Manifestations of sarcoidosis. Analysis of 145 patients, with review of nine series selected from the literature. Am J Med 1963; 35: 67-89.

31 Freundlich IM, Libshitz HI, Glassman LM, et al. Sarcoidosis. Typical and atypical thoracic manifestations and complications. Clin Radiol 1970; 21: 376-383.

32 Kirks DR, McCormick VD, Greenspan RH. Pulmonary sarcoidosis. Roentgenologic analysis of 150 patients. Am J Roentgenol Radium Ther Nucl Med 1973; 117: 777-786.

33 Winterbauer RH, Kraemer KG. The infectious complications of sarcoidosis: a current perspective. Arch Intern Med 1976; 136: 1356-1362.

34 Kaplan J, Johns CJ. Mycetomas in pulmonary sarcoidosis: nonsurgical management. Johns Hopkins Med J 1979; 145: 157-161.

35 Johns CJ, Zachary JB, MacGregor MI, et al. The longitudinal study of chronic sarcoidosis. Trans Am Clin Climatol Assoc 1983; 94: 173-181.

36 Pena TA, Soubani AO, Samavati L. Aspergillus lung disease in patients with sarcoidosis: a case series and review of the literature. Lung 2011; 189: 167-172.

37 Rubinstein I, Baum GL, Rosenthal T. Fungal infections complicating pulmonary sarcoidosis. J Infect Dis 1985; 152: 1360.

38 Ozseker ZF, Yilmaz A, Bayramgurler B, et al. Cavitary sarcoidosis: analysis of two cases. Respirology 2002; 7: 289-291.

39 Population Division of the Department of Economic and Social Affairs of the United Nations Secretariat, World Population Prospects: The 2008 Revision. www.un.org/esa/population/ publications/WPP2006RevVol_III/WPP2006RevVol_III_final.pdf Date last accessed: January 9, 2013.
40 Nunes H, Bouvry D, Soler P, et al. Sarcoidosis. Orphanet J Rare Dis 2007; 2: 46 .

41 Kappe R, Schulze-Berge A, Sonntag HG. Evaluation of eight antibody tests and one antigen test for the diagnosis of invasive aspergillosis. Mycoses 1996; 39: 13-23.

42 Coleman RM, Kaufman L. Use of the immunodiffusion test in the serodiagnosis of aspergillosis. Appl Microbiol 1972; 23: 301-308.

43 Longbottom JL, Pepys J, Clive FT. Diagnostic precipitin test in Aspergillus pulmonary mycetoma. Lancet 1964; 1: 588-589.

44 Severo LC, Geyer GR, Porto Nda S, et al. Pulmonary Aspergillus niger intracavitary colonization. Report of 23 cases and a review of the literature. Rev Iberoam Micol 1997; 14: 104-110.

45 Pasqualotto AC, Denning DW. An aspergilloma caused by Aspergillus flavus. Med Mycol 2008; 46: 275-278.

46 Denning DW, Park S, Lass-Florl C, et al. High frequency triazole resistance found in non-culturable Aspergillus fumigatus from lungs of patients with chronic fungal disease. Clin Infect Dis 2011; 52: 1123-1129.

47 Massard G, Roeslin N, Wihlm JM, et al. Traitement chirurgical de l'aspergillome pulmonaire et bronchique [Surgical treatment of pulmonary and bronchial aspergilloma]. Ann Chir 1993; 47: 141-146.

48 Denning DW, Pleuvry A, Cole DC. Global burden of chronic pulmonary aspergillosis as a sequel to pulmonary tuberculosis. Bull World Health Organ 2011; 89: 864-872.

49 Denning DW, Pleuvry A, Cole DC. Global burden of ABPA in adults with asthma and its complication chronic pulmonary aspergillosis. Med Mycol 2013; in press.

50 Carvalho A, Pasqualotto AC, Pitzurra L, et al. Polymorphisms in Toll-like receptor genes and susceptibility to pulmonary aspergillosis. J Infect Dis 2008; 197: 618-621.

51 Sambatakou H, Pravica V, Hutchinson IV, et al. Cytokine profiling of pulmonary aspergillosis. Int J Immunogenet 2006; 33: 297-302.

52 Denning DW. Invasive aspergillosis. Clin Infect Dis 1998; 26: 781-803.

53 Segal BH. Aspergillosis. N Engl J Med 2009; 360: 1870-1884.

54 Davies D, Somner AR. Pulmonary aspergillomas treated with corticosteroids. Thorax 1972; 27: 156-162.

55 Tercelj M, Salobir B, Zupancic M, et al. Antifungal medication is efficient in the treatment of sarcoidosis. Ther Adv Respir Dis 2011; 5: 157-162. 